\title{
Co-operative Banks and Financial Stability
}

\author{
Vincenzo Pacelli \\ Ionian Department in "Legal and Economic Systems of the Mediterranean: Society, Environment, \\ Cultures" \\ University of Bari "Aldo Moro" \\ Via Lago Maggiore (angolo Via Ancona)- 74121, Taranto, Italy
}

Francesca Pampurini

Department of Economic and Social Sciences

Catholic University of the Sacred Heart of Milan

Via Emilia Parmense, 84 - 29122 Piacenza, Italy

Anna Grazia Quaranta

Department of Economics and Law

University of Macerata

Via Armaroli, 43 - 62100 Macerata, Italy

\begin{abstract}
The paper analyzes whether co-operative banks are less involved than others in the mechanisms underlying the propagation and accentuation of systemic risk and therefore, if their presence, like a bearing, somehow manages to mitigate the final entity of this risk. We observe a set of Euro Area banks in 2018 with the aim of dividing them into homogeneous groups based on the values assumed by some indicators linked to systemic risk. It emerges that cooperative banks are more numerous in the groups in which the indicators show that the probability of contributing to systemic risk is lower.In literature, there are few studies on this particular topic and, to the best of our knowledge,none of them uses the procedure we propose.
\end{abstract}

\section{JEL Classification: G21 G28}

Keywords: Co-operative Banks; Business Models;Systemic Risk; Grouping Techniques.

\section{Introduction}

The co-operative banking system is a particular environment that is gaining more and more attention after the burst of the 2008 Global Financial Crisis for many reasons. First of all, it is well known from the empirical literature that co-operative and mutual banks proved to be able to survive to the crisis better than commercial banks; in addition, they suffered much less the problems linked to non-performing loans and they exhibited a higher degree of efficiency both during and after the crisis period.

The crucial role of co-operative banks in promoting local development is highlighted by an extensive theoretical and empirical literature. The historical success of mutual banks derives not only from their specific business model, but also from their peculiar and distinguishing corporate governance with member ownership. According to a copious literature, these features have probably allowed co-operative banks to better withstand financial crisis.

The European banking system is characterized by the massive presence of mutual banks that exhibit a business strategy very different from other kinds of credit institutions. Co-operative and mutual banks have historically played a crucial role in the financial systems of almost all European countries.It is very important to study this particular banking model since it is based on a particular organizational design, which is different from private banks that "restrict" their functioning in the interest of their shareholders. Their peculiar business model and institutional features provided them quite a success. In details, their business has a regional/local focus, andtheir main goals are the value creation for members and the construction of a long-term relationship based on trust. Moreover, the customer proximity and the traditional lending-based activity make them the major interlocutor for local communities in supplying a comprehensive range of financial services and so they are particularly active in lending to families and SMEs. Furthermore, the owners and providers of equity are not called shareholders but members and each member has only one vote in the annual general meetings regardless of the number of shares held. Co-operative and mutual banks are self-governed private organizations and, according to the "principle of identity", members are their main customers and conversely many of their clients are also members. 
So,there is a partial coincidence between members and customers and consequently thecustomers/members own and control the bank and they are fully involved in the decision-making process. Again, co-operative banks actively support the sustainable development of their territory by reinvesting a significant portion of their available profits back into the community.

This kind of institutional model presents both positive and negative implications. A first strength of the cooperative and mutual model derives from territorial proximity that allows to collect savings on a local basis. These resources are used to grant loans to households, SMEs and local authorities. The prudent management (EACB, 2016) represents a second advantage. This high level of prudence is due to many reasons. Most of co-operative and mutual banks' resources come from deposits. Secondly, they mainly provide retail banking products. Thirdly, the proximity allows co-operative and mutual banks to assess risks accurately. The intimate knowledge of customers should allow a better selection, increasing the credit quality and reducing the incidence of non-performing loans (Aiello et al, 2016). The long-term strategy, aimed at financing the economy and the development of communities rather than short term profit, represents a further element of structural stability. Co-operative banks are often well capitalized because their profits are largely held in reserve. Also, their governance has positive implications. Members/customers elect their own representatives to run their local bank. This fact should ensure that cooperative and mutual banks satisfy better the interests of the customers in their community.

On the other hand, a relevant limit of the co-operative and mutual business model is the members' weak incentive to monitor the performance of the managers (Bülbül et. al, 2013). This is due to the fact that "owners-members" can hardly benefit from policies that would increase the value of their shares because ownership stakes in cooperative banks are not easily marketable. For the same reason, members cannot exert pressure on management because they cannot accumulate a sufficient number of voting rights. There is no market in corporate control so that it is virtually impossible for hostile bids for ownership to take place. This could be seen as a disincentive for an efficient and good management (Aiello et al, 2016).

Despite international trends - e.g. globalization, deregulation, innovation - produced significant changes in mutual banks, they are still well distinguished in terms of operating model from other types of banks. Still today, they maintain a significant weight in the banking sector. According to statistics referred to 2019 from the European Association of Co-operative Banks ${ }^{1}$, there are about 3,135 local co-operative banks in Europe, with 80,5 million members, serving more than 209 million customers, and with an average market share of $20 \%$.

This research advances the literature in different ways. First, our results enhance the recent debate about the modernity of theco-operative and mutual banking system. Our results support the theory of mutual banks' survival during the financial crisis, demonstrating that the mutual business model is still able to meet customers' needs and, at the same time, preserve profitability and efficiency. These kinds of results are a useful instrument for managers, for policymakers and for European regulators.Furthermore,the aim of this paper is to study the real co-operative banking system contribution to the whole financial system systemic risk.In particular, we believe that the presence of co-operative banks has a positive effect because it helps reducing the level of systemic risk thanks to the anticyclical ability of these banks to exploit their proximity with the local territory and their strong knowledge of the customers.

To this aim, the paper wants to analyze whether co-operative banks are less involved than others in the mechanisms underlying the propagation and accentuation of systemic risk and therefore, if their presence, like a bearing, somehow manages to mitigate the final entity of this kind of risk. We believe that the result can be particularly interesting and useful for both the regulators, policy makers and the bank managers (taking strategic choices and assessing the adequacy of the business model to adopt).

Existing literature pointed out that during a crisis the banks that contribute more to the propagation of the systemic risk exhibit some common features; among them, they (i) suffer the worst losses in terms of CET1, (ii) strongly reduce the loans to the real economy, (iii) reduce their size and (iv)suffer an increase of the NPL ratio.

Therefore, starting from the main indicators coming from literature, we subdivide a set of different banks operating with different business models in order to analyse the characteristics of each obtained group in terms of those variables that are expected to have a certain impact on the level of systemic risk. This, with a particular attention to verify if the presence of co-operative banks is stronger in those groups that exhibit indicators values that may suggest a lower impact on systemic risk.

In literature, there are few studies on this particular topic and, to the best of our knowledge, none of them uses the procedure we propose. Our analysis focuses on a dataset composed of different kinds of banks operating in the Euro Area in 2018.

${ }^{1}$ The European Association of Co-operative Banks (EACB) represents 27 member institutions and cooperative banks. http://www.eacb.coop/en/home.html. 
The paper is organized as follows: Section 2 reviews the literature; Section 3 outlines the methodology; Section 4 describes data and variables used for the empirical analysis and illustrates theobtained results; Section 5 concludes.

\section{Literature Review}

The crucial role of mutual and co-operativebanks in promoting local development is highlighted by an extensive theoretical and empirical literature (Boscia et al., 2010; EACB, 2010; Bulbul et al., 2013; Fiordelisi and Mare, 2013; Chiaramonte et al., 2015; Clark et al., 2018; Pacelli et al. 2019). The historical success of mutual and cooperativebanks derives not only from their specific business model, but also from their peculiar and distinguishing corporate governance with member ownership. These features have probably allowed mutual and cooperativebanks to better withstand financial crisis.Many authors believe that co-operative banking model revealed a better resilience to the financial turmoil generated by the international financial crisis of 2007 (EACB, 2010).

Despite the presence of different definitions of the same phenomenon, we can say that systemic risk is often defined as the risk that the bankruptcy - or at least the pure perception of the probability of insolvency - of one or more financial intermediaries - or of a State too - can determine phenomena of generalized insolvency and serial bankruptcy involving many parties, with a contagion effect that spreads quickly through the market. The systemic risk, in other words, is the risk associated to the manifestation of an event capable of causing, through a propagation mechanism, structural effects on an entire economic system.

The initial shocks that can generate a propagation mechanism, and so, determine the occurrence of a systemic crisis are several and they can be classified into the following:

$\checkmark \quad$ crisis of one or more financial intermediaries or the pure perception of the risk of insolvency by (from) the aforementioned players (Nelson et al., 2014);

$\checkmark$ crisis of one or more sovereign states or the pure perception of the risk of insolvency by the aforementioned players (Beirne et al., 2013);

$\checkmark$ drop in the price of specific real or financial assets, among which the residential property (Cerutti et al., 2017);

$\checkmark$ liquidity pressures in financial markets that can determine the need for deposit withdrawal from the depositors and the resulting deleveraging phenomena and the selling of assets from the banks, that feed the prices collapse process of financial and real assets (Reinhart et al., 2013).

As a result of these initial shocks, the causes that determine the propagation of the shock to an entire economic system, generating the manifestation of the systemic risk, are the following:

high interconnection between the parties of the economic and financial system, in particular large exposure of the banks in the sovereign debt and in the interbank markets (Blundell-Wignall, 2012; Hoque et al., 2015);

$\checkmark \quad$ crisis of confidence in the workers and, in severe cases, panic, that determine a domino effect characterized by generalized and indiscriminate selling, assets prices reduction, credit restriction, failure and bank run (Calvo, 2012);

substantial information disparity in the financial markets, also due to the increasing complexity of the financial instruments, to the poor and asymmetric information and to the lacking of financial literacy (Flannery et al., 2013);

$\checkmark$ high debt of the parties of a financial system and so high financial dependence of debtors from creditors, that makes the entire system vulnerable in periods of crisis.

In response to the financial crisis that began in 2007, the studies on the systemic risk have increased significantly, in parallel with the increasing attention of the Supervisory Authorities and of the international governments, mainly focused on the strengthening of the financial intermediaries solidity as principal means to ensure the financial stability of an economic system (Acharya et al., 2009; Bengtsson, 2013; Lane, 2012; Brunnermeier, 2009; Brunnermeieret al., 2012).

\section{Methodology}

The aim of the paper is to understand whether co-operative banks are less involved than other kind of banks in the mechanism underlying the propagation and accentuation of systemic risk and therefore, if their presence somehow helps to mitigate the final entity of this risk. As stated before, there are many different definitions of systemic risk, but, in this study, we refer to the basic interpretation explained in the previous paragraph.

With more detail, starting running a cluster analysis, we willgroup the banks of our data set considering the (nonmulticollinearstandardized) information given by ten variables that can be divided in two sub-set. The first three indicators (that try to quantify the level of interbank loans and deposits and the sovereign debt held by each bank) should be able to capture the greater or lesser speed of risk propagation due to the interconnection of each bank with the interbank system and the public sector. The other seven indicators, on the other hand, should be able to provide a multifaceted information on the health status of each bank; by itself, a healthy bank, should in fact, by definition, not contribute - or contribute less - to total systemic risk. 
After having divided the considered banks into the most appropriate number of groups, we will study the composition of them and information will be given on the characteristics of each group, with a particular attention to the type of bank's specialization and, therefore, to the business model adopted. In other words, the aim of this second step is (i) toanalyze the characteristics of each obtained group in terms of other variables that are expected to have a certain impact on the level of systemic risk too and, in particular, (ii) to understand if the presence of cooperative banks is stronger in those groups that exhibit indicators values that may suggest a lower impact on systemic risk.

\section{Empirical Results}

Our analysis focuses on a dataset composed of different kinds of banks operating in the Euro Area in 2018. We downloaded the balance sheet data of the universe of the co-operative, commercial, saving and investment banks from the Bureau VanDijkdatabase.

Actually, the data collection process had been particularly difficult because, in order to obtain final robust information, we had to exclude all the banks that presented missing values in correspondence of the variables needed to develop our research. It is well known ${ }^{2}$, in fact, that to achieve significant results in multivariate analysis (and particularly in relation to the grouping techniques that will be implemented in this paper) the statistical units (in our case the banks) that show missing values should be left out.Consequently, this choice reduced the number of banks of the original dataset from 3716 to 1621 ; moreover, unfortunately, most of the remaining banks belong to the same country, that is Germany, and exhibit the same specialization, such as co-operative banks (see Table 1).Moreover, they are almost all unlisted $(95 \%)^{3}$.

For this reason, we cannot consider the dataset used as a statistical sample (for which inferential techniques should have been available),but it can be only considered as the set, such as the set of all the banks for which the very least information needed for the analysis are available.

Referring to previous literature, we wanted to take into account other variables too (among them, for example, the amount of loans to the public sector to consider another possible diffusion channel of systemic risk), but this kind of information was not available from any data provider in relation to unlisted banks that instead represent the most of our set. In Table 1 we present the cross tabulation of banks specialization by country, while in Table 2 there are the descriptive statistics of some relevant variables in our data set.

Table 1. Cross tabulation of banks specialization by country.

\begin{tabular}{|c|c|c|c|c|c|}
\hline Country & $\begin{array}{c}\text { Commercial } \\
\text { bank }\end{array}$ & $\begin{array}{c}\text { Co-operative } \\
\text { bank }\end{array}$ & $\begin{array}{c}\text { Investment } \\
\text { bank }\end{array}$ & $\begin{array}{c}\text { Savings } \\
\text { bank }\end{array}$ & Total \\
\hline AT & 13 & 7 & & 2 & 22 \\
\hline $\mathrm{BE}$ & 9 & 1 & & 1 & 11 \\
\hline $\mathrm{CY}$ & 6 & & & & 6 \\
\hline $\mathrm{EE}$ & 2 & & & & 2 \\
\hline FI & 7 & & & 4 & 11 \\
\hline FR & 10 & 36 & & 2 & 48 \\
\hline $\mathrm{DE}$ & 14 & 732 & 7 & 364 & 1,117 \\
\hline$\overline{\mathrm{GR}}$ & 6 & 1 & 1 & & 8 \\
\hline IE & 5 & & 1 & & 6 \\
\hline IT & 50 & 238 & 10 & 18 & 316 \\
\hline LT & 4 & & & & 4 \\
\hline LV & 4 & & & & 4 \\
\hline LU & 5 & & 1 & 1 & 7 \\
\hline MT & 6 & & & & 6 \\
\hline NL & 15 & 1 & & & 16 \\
\hline PT & 5 & 1 & 3 & 4 & 13 \\
\hline SK & 2 & & & 2 & 4 \\
\hline SI & 7 & 1 & & 1 & 9 \\
\hline ES & 7 & 1 & 1 & 2 & 11 \\
\hline Total & 177 & 1,019 & 24 & 401 & 1,621 \\
\hline
\end{tabular}

\footnotetext{
${ }^{2}$ Ferstl and Seres D. (2012); Roengpitya et al.(2014 e 2016); Everitt (2001); Lyvny et al.(1996); Romesburg (2004).

${ }^{3} \mathrm{We}$ ran some tests to understand if the strong presence of German banks could taint the conclusions, but we noticed that the results of the analysis are pretty much the same with and without the German banks. 
Table 2. Descriptive statistics of some relevant variables.

\begin{tabular}{|l|c|c|c|c|}
\hline & Mean & $\begin{array}{l}\text { Standard } \\
\text { Deviation }\end{array}$ & Skewness & $\begin{array}{l}\text { Variation } \\
\text { Coefficient }\end{array}$ \\
\hline Equity / Total assets & & 3.77 & 6.61 & 0.39 \\
\hline Total financial assets / Total assets & 9.76 & 12.57 & 0.88 & 0.56 \\
\hline Net Loans / Total assets & 22.48 & 14.70 & -0.92 & 0.23 \\
\hline Liquid assets / Total assets & 15.09 & 12.47 & 2.11 & 0.83 \\
\hline Total liabilities / Total assets & 90.24 & 3.77 & -6.61 & 0.04 \\
\hline Net loans \& advances to banks / Total assets & 7.31 & 7.33 & 3.32 & 1.00 \\
\hline Deposits from banks/Total assets & 13.60 & 10.52 & 2.15 & 0.77 \\
\hline Government securities/Total assets & 8.77 & 12.14 & 1.93 & 1.38 \\
\hline
\end{tabular}

The highest values of some (relative) variability index in Table 2 can be explained by the simultaneous presence of very large and very small banks in the same data set.

As underlined in Section 3, we wanted to group the banks of the data set considering the information given by ten variables (see Table 3) that can be divided into two sub-sets.

The first three indicators try to quantify the level of interbank loans and deposits and the sovereign debt held by each bank. To this aim, we respectively considered Net Loans \& Advances to Banks (I1), Deposits from Banks (I2) and Government Securities (I3)to Total Assets.

They should be able to capture the greater or lesser speed of systemic risk propagation due to the interconnection of each bank with both the interbank system and the public sector.

In particular, lower values of these three variables should indicate a lower probability for a bank to contribute to the systemic risk of the whole financial system. This because, as already underlined in literature:

- $\quad$ as for the first two indicators, the lower the participation in the interbank market of a bank, the lower its probability of being infected by critical situations of other banks and, therefore, the less the likelihood that this bank will amplify the systemic risk;

as for the third indicator, the lower the share of government securities held in a bank portfolio, the lower its probability of suffer the negative consequences of the failure of different countries and, therefore, the lower the probability that the systemic risk is amplified.

The other seven indicators considered are the TIER1 ratio(I4), the NPLs ratio(I5= Impaired Loans to Gross Customer Loans \& Advances ratio), the Liquidity ratio(I6=Liquid Assets to Deposits \& short-term funding ratio), the ROAE (I7 = Return on Average Equity), the ROAA (I8 =Return on Average Assets), the Cost to Income ratio (I9) and the z-score (I10) ${ }^{4}$.

As they are, respectively, indicators of the capitalization level, of the credit portfolio quality, of the liquidity and profitability level, of the efficiency degree and of the general insolvency risk (and so, instability), they should be able to provide a multifaceted information on the health status of each bank.

By itself, a healthy bank should in fact, by definition, not contribute (or contribute less) to total systemic risk. Therefore, a bank that has reached lower values of I5 and I9 and higher values of I4, I6, I7, I8 and I10 should have a lower probability to contribute to the systemic risk of the whole financial system. In Table 3 there are the descriptive statistics of the ten variables used to group the considered banks.

Table 3. Descriptive statistics of the ten variables used to group the considered banks.

\begin{tabular}{|c|c|c|c|c|}
\hline & Mean & $\begin{array}{l}\text { Standard } \\
\text { Deviation }\end{array}$ & Skewness & $\begin{array}{l}\text { Variation } \\
\text { Coefficient }\end{array}$ \\
\hline I1 = Net loans \& advances to banks / Total assets & 7.31 & 7.33 & 3.32 & 1.00 \\
\hline I2 = Deposits from banks/Total assets & 13.60 & 10.52 & 2.15 & 0.77 \\
\hline I3 = Government securities/Total assets & 8.77 & 12.14 & 1.93 & 1.38 \\
\hline I4 = Tier 1 ratio & 16.92 & 5.94 & 4.58 & 0.35 \\
\hline I5 = NPLs ratio & 3.99 & 5.89 & 4.33 & 1.48 \\
\hline I6 = Liquidity ratio & 19.04 & 23.81 & 9.77 & 1.25 \\
\hline I7 = ROAE & 2.22 & 6.65 & -8.83 & 3.00 \\
\hline I8 = ROAA & 0.21 & 0.62 & -8.71 & 2.92 \\
\hline I9 = Cost to Income Ratio & 75.89 & 67.34 & 25.43 & 0.89 \\
\hline I10 = z-score & $1,321.42$ & $10,867.04$ & 37.68 & 8.22 \\
\hline
\end{tabular}

\footnotetext{
${ }^{4}$ The z-score reflects the number of standard deviations by which returns would have to fall from the mean to wipe out bank equity. It is calculated dividing the sum of ROAA and Equity to Total Assets by the standard deviation of ROAA (Chiaramonteet al., 2015).
} 
As for Table 2, the highest values of some (relative) variability index in Table 3 can be explained by the simultaneous presence of very large and very small banks in the same data set.

After the well-known preliminary analysis required before implementing each multivariate procedure (i.e. the analysis to verify the possible presence of multivariate outliers in the data set and the analysis to assess the collinearity degree between the variables used) and having standardized the data, we run hierarchical and nonhierarchical (K-means) cluster analysis.As for the hierarchical approach, we tried a high number of combinations deriving from the consideration of different grouping algorithms and the distance measures. As a result, we obtained from the different approachesused slightly overlapping clusters and differences among them very dependent by the procedure used.

In other words, the groups obtained by the different procedures did not allow drawing the same general conclusions. Thus, starting from some more clear evidences, for example the number of groups to make - thatthe dendrograms indicated to be six - and a certain dominance of the first three variables for the purpose of grouping, we divided the analyzed banks according to the following steps:

1) first of all, we divided banks into three groups taking into account how many values of their first three indicators (I1, I2 and I3) were lower of the median value of each index calculated considering the whole set of banks. In particular, the first group includes the banks that exhibit values lower than the median of at least two indicators on three of which one had to be necessarily I3. In the second group,there are the banks that exhibit only one indicator's value lower than its median value and, finally, in the third group there are banks that had none indicator with a value lower than its median one. We decided to use the median values of the indicators after analyzing the distribution skewness of the different indexes.

2) then, within each group, banks were divided in two groups: in the first of them there are banks that registered at least four indicators values better than their median value, while in the second one there are banks that exhibit three or less indicators values better than their median value.

In Table 4and 5 the obtained results. The differences among the average values obtained in each the group in relation to the variables observed, were strongly significant using ANOVA tests ${ }^{5}$.

Table 4. Descriptive statistics of the grouping variables by group.

\begin{tabular}{|c|c|c|c|c|c|c|c|}
\hline & $\begin{array}{c}\text { I4 }=\text { Tier } \\
1 \text { ratio }\end{array}$ & $\begin{array}{c}\text { I5 }=\text { NPLS } \\
\text { ratio }\end{array}$ & $\begin{array}{c}\text { I6 }= \\
\text { Liquidity } \\
\text { ratio }\end{array}$ & $\begin{array}{c}\text { I7 = } \\
\text { ROAE }\end{array}$ & $\begin{array}{c}\text { I8 = } \\
\text { ROAA }\end{array}$ & $\begin{array}{c}\text { I9 = Cost } \\
\text { to Income } \\
\text { Ratio } \\
\end{array}$ & $\begin{array}{c}\mathbf{I 1 0}=\mathrm{z}- \\
\text { score }\end{array}$ \\
\hline \multicolumn{8}{|c|}{ Group 1 (Lowest probability of systemic risk propagation) } \\
\hline Mean & 17.26 & 3.07 & 15.17 & 2.60 & 0.25 & 72.82 & 550.10 \\
\hline Standard Deviation & 9.67 & 6.15 & 27.11 & 3.67 & 0.38 & 14.82 & 552.63 \\
\hline Skewness & 10.87 & 8.30 & 11.27 & 2.18 & -6.58 & 5.47 & 1.33 \\
\hline ve & 0.56 & 2.00 & 1.79 & 1.42 & 1.50 & 0.20 & 1.00 \\
\hline \multicolumn{8}{|c|}{ Group 2 (Medium probability of systemic risk propagation) } \\
\hline Mean & 16.38 & 3.27 & 12.61 & 2.79 & 0.27 & 75.43 & 706.56 \\
\hline Standard Deviation & 4.65 & 7.13 & 13.95 & 4.23 & 0.47 & 18.75 & 743.31 \\
\hline Skewness & 1.91 & 6.23 & 4.84 & 3.09 & 1.84 & 1.38 & 2.80 \\
\hline ve & 0.28 & 2.18 & 1.11 & 1.52 & 1.75 & 0.25 & 1.05 \\
\hline \multicolumn{8}{|c|}{ Group 3 (Highest probability of systemic risk propagation) } \\
\hline Mean & 15.96 & 3.15 & 15.78 & 3.25 & 0.31 & 74.45 & 665.60 \\
\hline Standard Deviation & 4.17 & 5.47 & 16.30 & 4.32 & 0.47 & 21.25 & $1,004.96$ \\
\hline Skewness & 2.70 & 6.44 & 3.38 & -1.66 & -0.77 & 3.74 & 3.83 \\
\hline ve & 0.26 & 1.74 & 1.03 & 1.33 & 1.52 & 0.29 & 1.51 \\
\hline \multicolumn{8}{|c|}{ Group 1.1 (Lowest probability of systemic risk propagation) } \\
\hline Mean & 18.20 & 2.54 & 16.24 & 3.48 & 0.36 & 68.82 & 533.47 \\
\hline Standard Deviation & 7.50 & 5.52 & 24.22 & 3.64 & 0.25 & 9.30 & 545.61 \\
\hline Skewness & 5.05 & 10.13 & 10.83 & 9.81 & 2.94 & 0.28 & 1.46 \\
\hline ve & 0.41 & 2.18 & 1.49 & 1.04 & 0.70 & 0.14 & 1.02 \\
\hline \multicolumn{8}{|c|}{ Group 1.2 (Low probability of propagation) } \\
\hline Mean & 16.29 & 3.63 & 14.07 & 1.67 & 0.14 & 76.97 & 567.40 \\
\hline Standard Deviation & 11.42 & 6.71 & 29.82 & 3.48 & 0.44 & 18.03 & 560.16 \\
\hline
\end{tabular}

${ }^{5}$ Data are available upon request.

14 


\begin{tabular}{|l|c|c|c|c|c|c|c|}
\hline Skewness & 12.16 & 7.16 & 11.36 & -6.46 & -8.20 & 5.68 & 1.21 \\
\hline vc & 0.70 & 1.85 & 2.12 & 2.08 & 3.29 & 0.23 & 0.99 \\
\hline \multicolumn{7}{|l|}{} \\
\hline
\end{tabular}

Table 5. Composition of the groups by category of bank.

\begin{tabular}{|c|c|c|c|c|}
\hline Commercial banks & Investment banks & Savings banks & Co-operative banks & Total \\
\hline \multicolumn{5}{|l|}{ Group 1} \\
\hline 27 & 4 & 80 & 557 & 668 \\
\hline $4 \%$ & $1 \%$ & $12 \%$ & $83 \%$ & $100 \%$ \\
\hline \multicolumn{5}{|l|}{ Group2 } \\
\hline 54 & 7 & 145 & 286 & 492 \\
\hline $11 \%$ & $1 \%$ & $29 \%$ & $58 \%$ & $100 \%$ \\
\hline \multicolumn{5}{|l|}{ Group 3} \\
\hline 96 & 13 & 176 & 176 & 461 \\
\hline $21 \%$ & $3 \%$ & $38 \%$ & $38 \%$ & $100 \%$ \\
\hline \multicolumn{5}{|l|}{ Group 1.1 } \\
\hline 11 & 1 & 20 & 300 & 332 \\
\hline $3 \%$ & $0 \%$ & $6 \%$ & $90 \%$ & $100 \%$ \\
\hline \multicolumn{5}{|l|}{ Group 1.2} \\
\hline 16 & 3 & 60 & 257 & 336 \\
\hline $5 \%$ & $1 \%$ & $18 \%$ & $76 \%$ & $100 \%$ \\
\hline \multicolumn{5}{|l|}{ Group 2.1 } \\
\hline 31 & 2 & 43 & 163 & 239 \\
\hline $13 \%$ & $1 \%$ & $18 \%$ & $68 \%$ & $100 \%$ \\
\hline \multicolumn{5}{|l|}{ Group 2.2} \\
\hline 23 & 5 & 102 & 123 & 253 \\
\hline $9 \%$ & $2 \%$ & $40 \%$ & $49 \%$ & $100 \%$ \\
\hline \multicolumn{5}{|l|}{ Group 3.1 } \\
\hline 62 & 8 & 58 & 117 & 245 \\
\hline $25 \%$ & $3 \%$ & $24 \%$ & $48 \%$ & $100 \%$ \\
\hline \multicolumn{5}{|l|}{ Group 3.2} \\
\hline 34 & 5 & 118 & 59 & 216 \\
\hline $16 \%$ & $2 \%$ & $55 \%$ & $27 \%$ & $100 \%$ \\
\hline
\end{tabular}

\section{Discussion and Conclusion}

The results in the first part of Table 5 seem to show that moving from group 1 (that includes the banks that exhibit values lower than the median of at least two indicators on three of which one had to be necessarily I3) to group 3 (in which there are banks that had none indicator with a value lower than its median one), as the systemic risk diffusion possibility increases, the probability to find a co-operative bank in that group decreases (from $83 \%$ to $38 \%)$. 
Moreover, analyzing the characteristics of each one of the six described groups(Table 4) it is possible to state that:

$\checkmark$ Group 1.1 includes the banks that should impact less than ever on systemic risk (the best ever in this regard) since they are those that, at the same time, propagate less and should be healthy from a general managerial point of view. Therefore, for them the probability to contribute to the whole systemic risk is absolutely the lowest. In this group the percentage of co-operative banks is about $90 \%$ (Table 5);

$\checkmark$ Group 1.2 includes the banks that, later on, should have a little impact on systemic risk,although this impact is greater with respect to that of the previous group. This because they are banks with a low rate of systemic risk diffusion but, at the same time, they exhibit some problems from a general managerial point of view (so, they are a bit more dangerous than those included in group 1.1). Therefore, for them the probability to contribute to the whole systemic risk is low, but not the lowest. In this group the percentage of co-operative banks is about $76 \%$ (Table 5);

$\checkmark \quad$ Group 2.1 includes the banks that should have a medium impact on systemic risk. In particular, they are healthy banks that should diffuse averagely the systemic risk. Therefore, for them the probability to contribute to the whole systemic risk is medium. In this group the percentage of co-operative banks is about 68\% (Table 5);

$\checkmark$ group 2.2 includes the banks that, later on,should have a medium-high impact on systemic risk. This because they show, at the same time, a medium capacity in diffusing the systemic risk and some managerial problems. For this reason, their probability to contribute to the whole systemic risk is medium-high. In this group the percentage of co-operative banks is about $49 \%$ (Table 5);

$\checkmark$ Group 3.1 includes the banks that should have a high impact on systemic risk. In particular, since they seem to be healthy banks from a managerial point of view, they show a high capacity in propagating the systemic risk. Therefore, for them the probability to contribute to the whole systemic risk is high. In this group the percentage of co-operative banks is about $48 \%$ (Table 5).

$\checkmark$ Finally, group 3.2 includes the banks that should have anabsolutely very high impact on systemic risk. These are "non-healthy" banks with a high systemic risk diffusion probability. In this group the percentage of cooperative banks collapse to about 27\% (Table 5);

These last results seem to confirm the evidence coming from the upper part of Table 5 as it seems clear that, as we expected, moving towards groups with a higher systemic risk diffusion probability - deriving both from a higher propagation probability and a worst performance - co-operativebanks are less numerous in percentage.

In any case, what we have said should be confirmed by a wider and more diversified data set of banks as well as including other information coming from additional variables.

Indeed, as discussed in Section 4, we:

(i) cannot consider the dataset used as a statistical sample(for whichinferentialtechniquesshouldhavebeenavailable), since it is only the set of all the banks for which the very least information needed for the analysis were available;

(ii) want to take into account other variables frequently used in literature, whose data

- were not available for different reasons. It is the case of the amount of loans to the public sectorthat can be consider as another possible diffusion channel of systemic risk. This kind of information was not available from any data provider in relation to unlisted banks that instead represent the most of our set, or

- $\quad$ it was not possible to use due to the insufficient geographical diversification of the analysed banks. It is the case of some macroeconomic variables - theGDP, the ratio of debt over GDP, the rating of each country, the average government bonds yield and the spread of each country, the activity of the stock exchange market, the level of inflation, the level of real estate prices, the expectations and consensus of investors, firms and savers and the average efficiency of the banking sector - that literature links to systemic risk as its forerunners.

The not much homogeneous results provided the different cluster analysis approaches could also be the consequence of many of the aforementioned problems.

For all this reason, we have to consider the empirical evidences described in this section as promising, but very preliminary results and therefore weakened by a certain level of uncertainty that we hope to reduce as soon as possible.

\section{References}

Acharya, V.V., \&Richardson, M. (2009). Restoring Financial Stability: How to Repair a Failed System. New York: John Wiley \& Sons.

Aiello F., \&Bonanno G. (2016).Bank efficiency and local market conditions. Evidence from Italy. Journal of Economics and Business, 83, 70-90. 
Bengtsson, E. (2013). Shadow banking and financial stability: European money market funds in the global financial crisis. Journal of International Money and Finance, 32, 579-594.

Blundell-Wignall, A. (2012). Solving the financial and sovereign debt crisis in Europe. OECD Journal: Financial Market Trends, 2011(2), 201-224.

Brunnermeier, M. K., \&Oehmke, M. (2013). Bubbles, financial crises, and systemic risk. Handbook of the Economics of Finance, 2, 1221-1288.

Brunnermeier, M. K. (2009). Deciphering the liquidity and credit crunch 2007-2008. Journal of Economic perspectives, 23(1), 77-100.

Boscia, V., Carretta, A.,\&Schwizer, P.(2010). Co-operative Banking in Europe: Case Studies. UK: Palgrave Macmillan Publisher.

Blundell-Wignall A., Atkinson, P.,\&Roulet, C. (2013). Bank Business Models and the separation Issue. OECD Journal: Financial Market Trends, 2013(2).

Bülbül D., Schmidt, R. H.,\&Schüwe,r U. (2013). Savings Banks and Co-operative Banks in Europe. SAFE Policy papers, White Paper Series 5.

Calvo, G. (2012). Financial crises and liquidity shocks a bank-run perspective. European Economic Review, 56(3), 317-326.

Cerutti, E., Dagher, J., \&Dell'Ariccia, G. (2017). Housing finance and real-estate booms: A cross-country perspective. Journal of Housing Economics, 38, 1-13.

Chiaramonte, L., Poli, F. \&Oriani, M.E. (2015) Are Co-operative Banks a lever for promoting Bank stability? Evidence from the Recent Financial Crisis in OECD Countries. European Financial Management, 21(3), 491-523.

ClarkE. A., Mare D., \& Radić, N. (2018).Co-operative banks: What do we know about competition and risk preferences?. Journal of International Financial Markets, Institutions \& Money, 52, 90-101.

EACB (2010). European co-operative banks in the financial and economic turmoil. First assessments.

EACB (2016). Corporate Governance in Co-operative Banks: Key Features, 3 February.

Edurkar, A., \&Dattatrya, G. (2016). 2016 WP Application of factors and Cluster Analysis for an Evaluation of Business. MPRA Paper, 73536.

Everitt, B.S., Landau, S., \&Leese, M. (2001).Cluster Analysis. Oxford: Oxford University Press, Fourth Edition.

Farnè, M., \&Vouldis, A. (2018). Business Models of the Banks in the Euro Area - European Central Banks Working Papers Series, 2018.

Flannery, M. J., Kwan, S. H., \&Nimalendran, M. (2013). The 2007-2009 financial crisis and bank opaqueness. Journal of Financial Intermediation, 22(1), 55-84.

Lyvny, M., Ramakrishnan, R., \&Zhang, T. (1996).BIRCH: an efficient data clustering method for very large databases. Zurigo: SIGMOD.

Ferstl, R., \&Seres, D. (2012). Clustering Austrian bank's Business Models and Peer Groups in the European Banking Sector. Financial Stability ReportOesterreichischeNationalbank (Austrian Central Bank), 24 - 7995.

Fiordelisi,F., D. \&Mare, S. (2013).Probability of default and efficiency in co-operative banking, Journal of International Financial Markets, Institutions and Money, 26 (C), 30-45.

Hoque, H., Andriosopoulos, D., Andriosopoulos, K., \&Douady, R. (2015). Bank regulation, risk and return: Evidence from the credit and sovereign debt crises. Journal of Banking \& Finance, 50, 455-474.

Lane, P. R. (2012).The European sovereign debt crisis. Journal of Economic Perspectives, 26(3), 49-68.

Nelson, S. C., \&Katzenstein, P. J. (2014). Uncertainty, risk, and the financial crisis of 2008. International Organization, 68(2), 361-392.

Oshumi, N. (1980).Evaluation procedure of agglomerative hierarchical clustering methods by fuzzy relations in DidayE.:Data Analysis and Informatics, Amsterdam: North Holland.

Pacelli, V., Pampurini, F., \&SylosLabini, S. (2019). The peculiarity of the co-operative and mutual model: evidence from the European banking sector. Journal of Financial Management, Markets and Institutions, 7(1),1-29.

Reinhart, M. C., \& Rogoff, M. K. (2013).Financial and sovereign debt crises: some lessons learned and those forgotten. International Monetary Fund, 13, 266-278.

Roengpitya, R., Tarashev, N., \&Tsatsaronis, K. (2014). BIS Bank Business Models. BIS Quarterly Review, December 2014.

Roengpitya, R., Tarashev, N., Tsatsaronis, K., \& Villegas, A. (2016). Bank Business Models: Popularitu and Performance. BIS Working Papers, 682.

Romengsburg,H.C. (2004).ClusterAnalysis for researchers. Boston: LULU PR. 